\title{
Paidéia: Management Report - 2018
}

\author{
Paidéia: Relatório de Gestão - 2018
}

\section{Paidéia: Informe de Administración - 2018}

\author{
Manoel Antônio dos Santos ${ }^{1}$ (D) https://orcid.org/0000-0001-8214-7767 \\ Universidade de São Paulo, Ribeirão Preto-SP, Brazil
}

In this Management Report, we present indicators that give visibility to the editorial management of Paidéia for the year 2018. With the publication of this document, we preserve the tradition of presenting to the scientific community a balance of what the journal has produced in the previous year, making explicit the modus operandi of the processing of the manuscripts in the period.

The dissemination of scientific production is backed by a rigorous peer review process. To systematize information relative to the editorial process, it is possible to place the contribution of Paidéia in the contemporary scenario of scientific publications in the Humanities field, particularly Psychology.

This report is divided into the following sections: Editorial Policy and Arbitration Criteria, Editorial Process - 2018, and Final Considerations.

\section{Editorial Policy and Arbitration Criteria}

With its first publication in 1991, since 2018 Paidéia has adopted the rolling pass system. Paidéia is affiliated with the Psychology Graduate Program of the Faculdade de Filosofia, Ciências e Letras de Ribeirão Preto, Universidade de São Paulo - FFCLRP-USP. The Paidéia journal includes research that addresses a problem clearly related to Psychology, specifically in the areas: Psychology ofHealth, Developmental Psychology, School and Educational Psychology, Social Psychology and Psychological Evaluation. Paidéia accepts manuscripts based on the different theoretical-methodological approaches acknowledged by Psychology. The published articles should fall into the categories: research report, theoretical study, or systematic literature review.

In 2018, Paidéia completed 28 years of existence. Since its founding in August 1991, 29 volumes have been published and its collection is fully available through free access provided by the SciELO collection. The volumes are conspicuous for their diversity and breadth of topics, as well as for the plurality of methodological designs contained in the articles. The editorial line is generalist, considering the

${ }^{1}$ Correspondence address: Universidade de São Paulo. Faculdade de Filosofia, Ciências e Letras de Ribeirão Preto. Departamento de Psicologia. Av. Bandeirantes, 3900, Ribeirão Preto-SP, Brazil, CEP 14.040-901. E-mail: masantos@ffclrp.usp.br theoretical-methodological, epistemological and thematic diversity that pervades the Psychology area.

In terms of the classification in the Qualis Journals system, in the area of Psychology (Qualis Journals Commission of Psychology, 2015), Paidéia ascended from the B1 stratum, its status until 2011, to A1, the highest ranking evaluation position, which demonstrates the recognition of the prominent place that the journal occupies within the Brazilian scientific publications.

The prestige given to Paidéia within the scientific community is due to its selective policy of disseminating quality knowledge. Rigorous and thorough assessment is sustained with the support of a highly qualified Editorial Board, structured according to the areas and themes addressed in the articles submitted for consideration. This Council consists of significant names of the academic community, in both the national and international contexts. The processing of the manuscripts is the responsibility of an Editorial Commission composed of Associate Editors, the majority of whom are professors linked to the Graduate Psychology Program of FFCLRP-USP. This commission coordinates the rigorous peer review process, by utilizing ad hoc consultants with recognized competence, who have the task of evaluating and improving the manuscripts submitted for consideration.

To consolidate its visibility at the national and international level, Paidéia is indexed in a solid set of national and international databases (or full text portals) when compared to the other Brazilian journals in the field of Psychology. Our journal has been indexed in the following databases: SciELO Scientific Electronic Library Online (FAPESP/BIREME), Scopus (Elsevier), PsycINFO - Psychological Abstracts (American Psychological Association), LILACS - Literatura Latino-Americana e do Caribe em Ciências da Saúde (Centro Latino-americano y de Caribe de Informaciones en Ciencias de la Salud), CLASE - Citas Latinoamericanas en Ciências Sociales y Humanidades (Universidad Nacional Autónoma de México), PSICODOC (Colégio Oficial de Psicólogos de Madrid / Universidad Complutense de Madrid), DOAJ Directory of Open Access Journals, Ulrich's International Periodicals Directory, Catálogo Latindex, IRESIE (Universidad Nacional Autónoma de México), Index-Psi Periódicos (CFP/PUCCAMP), REDALYC - Red de Revistas Científicas de América Latina y el Caribe, España y Portugal, Portal de Revistas da USP (Universidade de São Paulo), ProQuest (CSA) - Databases, EBooks and Technology for 
Research, EBSCO - Information Services, Cengage Learning, Dialnet (Universidad de La Rioja), OAJI - Open Academic Journals Index, Index Copernicus International (IC Journal Master Listt), HINARI - Access to Research in Health Programme, ResearchGate, EZB - Electronic Journals Library (Universität Regensburg - Germany), HEAL Link - Hellenic Academic Libraries Link, and Socolar (China Educational Publications Import and Export Corporation - CEPIEC).

The submission of manuscripts is fully computerized, through the ScholarOne (Clarivate Analytics) provided by SciELO. The journal adopts a blind review evaluation system, which preserves the anonymity of the authors and reviewers. The texts submitted for consideration must primarily fall within the research report category. In each issue approximately 39 original research articles are published. As part of the new editorial policy of the journal, the Editorial Board decided to invest heavily in attracting articles that give visibility to research results derived from original empirical studies with quantitative or qualitative designs. The potential to make an impact in the area of knowledge is also a criterion for the selection of the manuscripts for publication. To be selected for publication, the manuscripts must be of international interest, rather than just local.

With regard to financing sources, Paidéia has relied on support from financial resources received annually from the Periodical Scientific Publications Support Program of USP and from the Scientific Publications Support Program of the National Council for Scientific and Technological Development (CNPq), as well as the support of the Graduate Psychology Program of FFCLRP-USP.

The publication standards are included at the end of each issue, which are available online in the languages: Portuguese, English, and Spanish. Those standards (Instructions to the Authors) are available on the SciELO page (http://www. scielo.br/paideia). The final issue of each volume provides the list of ad hoc evaluators, who contributed to the essential task of reviewing the manuscripts during the year.

Regarding the manuscript arbitration process, Paidéia adopts the mechanism of double-blind review by peers of recognized competence within the scientific community. Thus, the identities of the authors and of the ad hoc consultants are kept in strict confidentiality. The texts submitted for review should be in accordance with the guidelines of the publication standards and may be accepted or rejected by the Editorial Board, based on the recommendations of its members and the ad hoc consultants selected to enhance the evaluation process.

In relation to the availability of the content, Paidéia adopts the Creative Commons License, Attribution Non-commercial CC BY-NC. With this license it is permitted to access, download, copy, print, share, reuse, and distribute the articles, provided it is for noncommercial use and includes the citation of the source, giving appropriate credit to the journal. In such cases, no permission is required from the authors or the publishers.

Another aspect that distinguishes Paidéia in the scenario of Psychology publications is the systematic and periodic provision of information regarding the management process of the journal. In the first issue of each volume/year we publish a
Management Report, in which we seek to provide visibility and transparency to the work consolidated in the previous year. This document contains objective indicators to measure the progress of the journal, such as the processing time of the manuscripts, the origin of the authors who have their articles published, and the institutional origins of the reviewers/ad hoc consultants, among other topics of interest (Santos, 2016, 2017, 2018).

\section{Editorial Process - 2018}

When considering the editorial process of Paidéia in 2018 , it can be observed that the average processing time of the manuscripts was approximately six months. In this year, the journal received 103 new manuscripts, of which one was approved, 74 rejected and 28 were still in the evaluation process in December of 2018, (Table 1). Considering the manuscripts for which the editorial process was terminated in 2018 $(n=103)$, the journal approved $28.16 \%$ and rejected $71.84 \%$.

Table 1

Editorial Situation of the Manuscripts Submitted to Paidéia in 2018

\begin{tabular}{lr}
\hline Final decision & $n$ \\
\hline Received (Total) & 103 \\
Approved & 1 \\
Rejected & 74 \\
In the editorial process & 28 \\
\hline
\end{tabular}

Note. Mean time between submission and publication in $2018=18$ months.

Manuscripts submitted in 2018 were classified in the following categories: (a) Research report (90.3\%) and (b) Systematic literature review $(9.7 \%)$, as presented in Table 2.

Table 2

Category of the Manuscripts Submitted to Paidéia in 2018

\begin{tabular}{lrr}
\hline Type of manuscript & $n$ & $\%$ \\
\hline Research report & 93 & 90.3 \\
Systematic literature review & 10 & 9.7 \\
In the editorial process & 103 & 100.0 \\
\hline
\end{tabular}

As presented in Table 3, in 2018, volume 28, 39 articles and one systematic literature review were published, as well one management report. The publications were classified into the following categories: (a) Research report (98\%) and (b) Systematic literature review (2\%),

Table 3

Category of the Manuscripts Published in Paidéia in 2018

\begin{tabular}{lrr}
\hline Type of manuscript & $n$ & $\%$ \\
\hline Research report & 39 & 100.0 \\
Systematic literature review & 0 & 0.0 \\
In the editorial process & & 39 \\
\hline
\end{tabular}


Figure 1 shows the evolution of the number of manuscripts submitted and their fate in the triennium 20162018. These results highlight the rigorous analysis of the manuscripts selected for publication.

Regarding the institutional affiliation of the authors, Table 4 shows that Paidéia published articles originating from 32 Brazilian universities/colleges/institutes, with a predominance of the Universidade São Francisco. There was a reasonable increase in the amount of articles with authors affiliated with international institutions, mainly from
Spain and Portugal. It should be noted that the authors of the published articles are linked to a variety of higher education institutions, public, private and confessional, of various states of the Brazilian federation and abroad. In 2018, there was a predominance of federal universities over state ones

Reviewers (from $5.8 \%$ in 2017 to $7.6 \%$ in 2018). Furthermore, the important collaboration of international evaluators can be noted, $15.2 \%$ (Table 5).

Figure 2 shows the percentile distribution of te ad hoc consultants according to geographic origin.

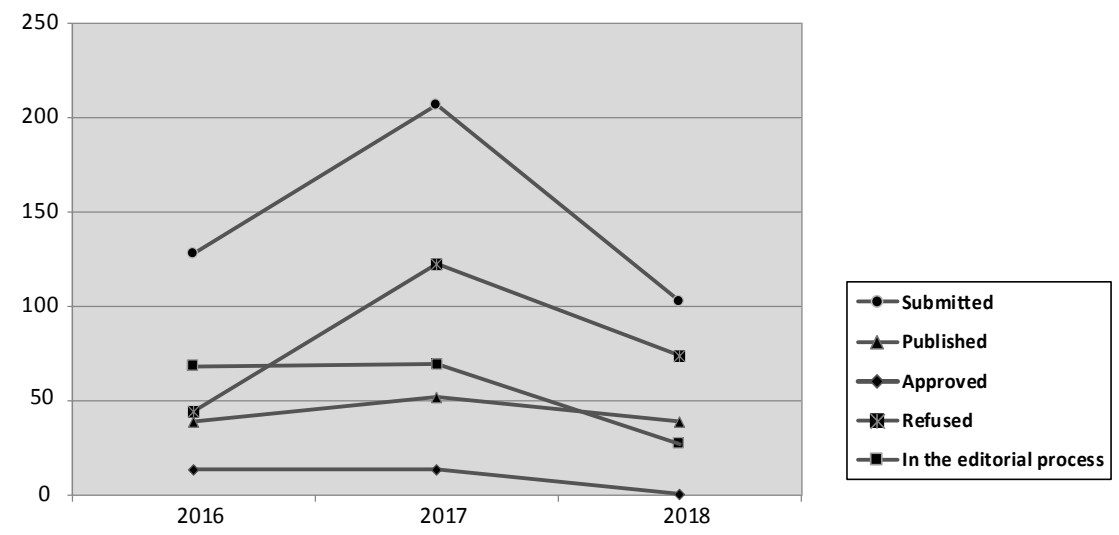

Figure 1. Number of manuscripts submitted to Paidéia and their editorial outcome in the triennium 2016-2018.

Table 4

Institutional Origin of the Authors who Published in Paidéia in 2018

\begin{tabular}{|c|c|c|}
\hline National institutions & $n$ & $\%$ \\
\hline Universidade São Francisco-SP & 17 & 17.1 \\
\hline Universidade Federal de São Carlos-SP & 10 & 10.0 \\
\hline Universidade de São Paulo-SP & 7 & 7.1 \\
\hline Universidade do Vale do Rio dos Sinos-RS & 7 & 7.1 \\
\hline Universidade Federal de Pernambuco-PE & 5 & 5.1 \\
\hline Universidade Salgado de Oliveira-RJ & 5 & 5.1 \\
\hline Pontifícia Universidade Católica do Rio Grande do Sul-RS & 4 & 4.1 \\
\hline Universidade Federal do Espírito Santo-ES & 4 & 4.1 \\
\hline Universidade Federal do Pará-PA & 4 & 4.1 \\
\hline Universidade Federal do Rio Grande do Sul-RS & 4 & 4.1 \\
\hline Universidade Federal de São João del-Rei-MG & 4 & 2.0 \\
\hline Pontifícia Universidade Católica de São Paulo-SP & 2 & 2.0 \\
\hline Universidade de Passo Fundo-RS & 2 & 2.0 \\
\hline Universidade Estadual de Londrina-PR & 2 & 2.0 \\
\hline Universidade Estadual Paulista-SP & 2 & 2.0 \\
\hline Universidade Federal da Bahia-BA & 2 & 2.0 \\
\hline Universidade Federal da Paraíba-PB & 2 & 2.0 \\
\hline Universidade Federal de Juiz de Fora-MG & 1 & 1.0 \\
\hline Pontifícia Universidade Católica de Campinas-SP & 1 & 1.0 \\
\hline Universidade Estadual de Campinas-SP & 1 & 1.0 \\
\hline Universidade Federal do Rio de Janeiro-RJ & 1 & 1.0 \\
\hline Universidade Federal do Triângulo Mineiro-MG & 1 & 1.0 \\
\hline
\end{tabular}




\begin{tabular}{|c|c|c|}
\hline National institutions & $n$ & $\%$ \\
\hline Fundação de Ensino e Pesquisa de Itajubá-MG & 1 & 1.0 \\
\hline Universidade Federal Fluminense, Niterói-RJ, Brazil & 1 & 1.0 \\
\hline Instituto de Pós-Graduação e Graduação-GO & 1 & 1.0 \\
\hline Natura Innovation-SP & 1 & 1.0 \\
\hline Pontifícia Universidade Católica de Goiás-GO & 1 & 1.0 \\
\hline Universidade do Estado do Rio de Janeiro-RJ & 1 & 1.0 \\
\hline Universidade Católica de Petrópolis-RJ & 1 & 1.0 \\
\hline Instituto Federal de Educação Ciência e Tecnologia de Goiás-GO & 1 & 1.0 \\
\hline Universidade Federal de Mato Grosso-MT & 1 & 1.0 \\
\hline Universidade Federal de Viçosa-MG & 1 & 1.0 \\
\hline Total & 99 & 100.0 \\
\hline International institutions & $n$ & $\%$ \\
\hline Sapienza Rome University, Rome, Italy & 3 & 18.75 \\
\hline Universidade do Porto, Porto, Portugal & 2 & 12.5 \\
\hline Universidade de Lisboa, Lisboa, Portugal & 2 & 12.5 \\
\hline Secretaria Regional de Educação, Madeira, Portugal & 2 & 6.25 \\
\hline Cardiff University, Cardiff, United Kingdom & 1 & 6.25 \\
\hline University of Bath, Bath, United Kingdom & 1 & 6.25 \\
\hline Massey University, Auckland, New Zealand & 1 & 6.25 \\
\hline Texas Tech University, Lubbock-TX, United States of America & 1 & 6.25 \\
\hline Norwegian University of Science and Technology, Trondheim, Norway & 1 & 6.25 \\
\hline Universidad Complutense de Madrid, Madrid, Spain & 1 & 6.25 \\
\hline Hospital Universitario de Getafe, Getafe, Spain & 1 & 6.25 \\
\hline Total & 16 & 100.0 \\
\hline
\end{tabular}

Table 5

Distribution of the ad hoc Consultants of Paidéia According to Their Geographic Origin $(N=119)$ in 2018

\begin{tabular}{|c|c|c|}
\hline International Countries & $n$ & $\% *$ \\
\hline Portugal & 13 & 11.0 \\
\hline Colombia & 4 & 3.4 \\
\hline London & 1 & 0.8 \\
\hline Subtotal & 18 & 15.2 \\
\hline National States & $n$ & $\% *$ \\
\hline \multicolumn{3}{|l|}{ Southeastern Region } \\
\hline São Paulo & 38 & 31.9 \\
\hline Minas Gerais & 16 & 13.4 \\
\hline Rio de Janeiro & 13 & 11.0 \\
\hline Subtotal & 67 & 56.3 \\
\hline \multicolumn{3}{|l|}{ Southern Region } \\
\hline Rio Grande do Sul & 7 & 5,9 \\
\hline Paraná & 5 & 4.2 \\
\hline Santa Catarina & 4 & 3.4 \\
\hline Subtotal & 16 & 13.5 \\
\hline National States & $n$ & $\% *$ \\
\hline \multicolumn{3}{|l|}{ Central-Western Region } \\
\hline Federal District & 6 & 5.1 \\
\hline Mato Gosso do Sul & 3 & 2.5 \\
\hline
\end{tabular}




\begin{tabular}{lll}
...continuation & & \\
\hline Subtotal & 9 & 7.6 \\
\hline Northeastern Region & 3 & 2.5 \\
Bahia & 3 & 2.5 \\
Paraíba & 1 & 0.8 \\
Rio Grande do Norte & 1 & 0.8 \\
Piauí & 8 & 6.6 \\
Subtotal & & \\
Northern Region & 1 & 0.8 \\
Pará & 1 & 0.8 \\
Subtotal & 1 & \\
\hline
\end{tabular}

Note. Calculation based on the total of 119 advisors who collaborated with the journal until December, 2018.

Regarding the origins of the ad hoc consultants, the predominance should be noted of reviewers from the universities of São Paulo (38\%) which, added to the evaluators from other institutions within the Southeastern, totaled $56.3 \%$ of the body of reviewers. The Southern region contributed $13.5 \%$ of the ad hoc evaluators; the Central-Western region contributed $7.6 \%$; while the Northeastern region had a participation of $6.6 \%$ and the Northern region $0.8 \%$.
These results show that the number of evaluators from the Southeastern had a slight decrease when compared to $2017(57 \%)$. Thus, a slight increase was found for the Northeastern reviewers (from $5.8 \%$ in 2017 to $6.6 \%$ in 2018) and for the Central-Western reviewers (from 5.8\% in 2017 to $7.6 \%$ in 2018). Furthermore, the important collaboration of international evaluators can be noted, 15.2\% (Table 5).

Figure 2 shows the percentile distribution of te ad hoc consultants according to geographic origin.

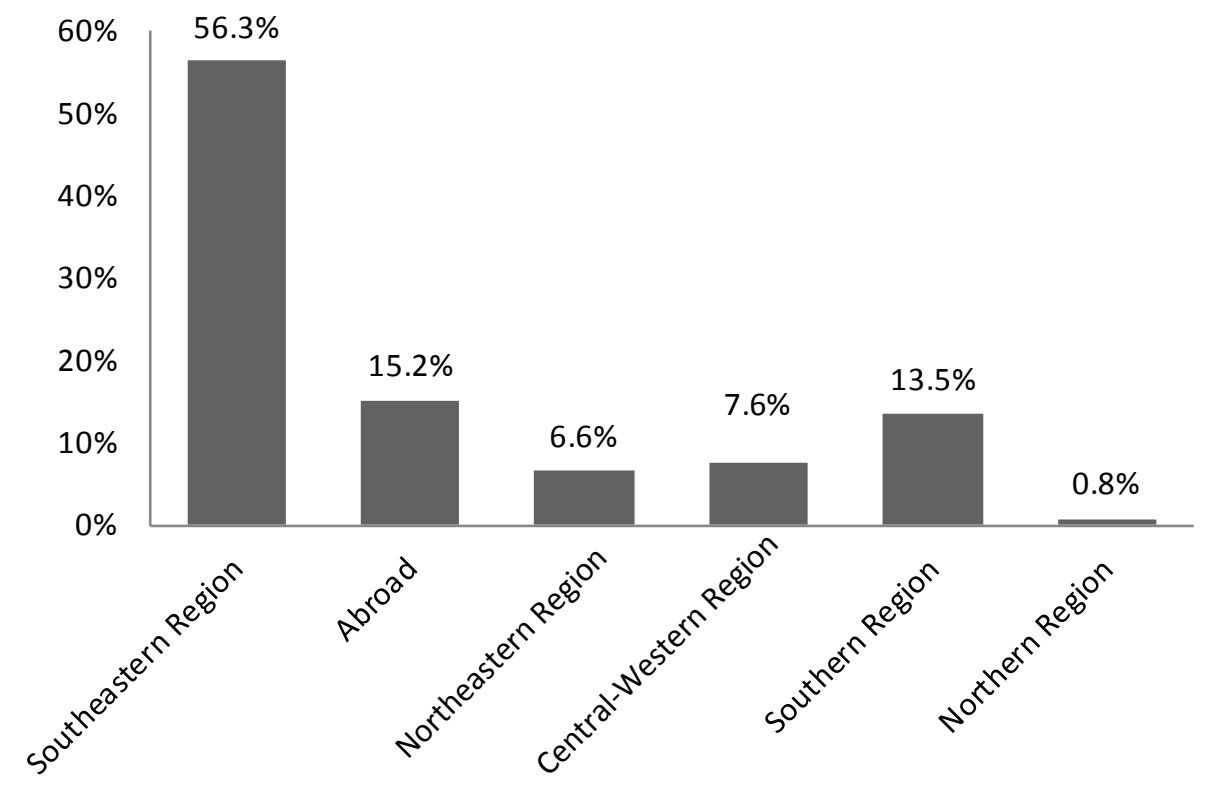

Figure 2. Distribution of the ad hoc consultants who collaborated with Paidéia in 2018 according to their region of origin.

\section{Final Considerations}

In recent years, Paidéia has worked hard to consolidate itself as one of the most prestigious Psychology publications in the Brazilian context. With true entrepreneurial spirit, coordinated actions have been implemented to create objective conditions for the internationalization of the journal, which enhanced the visibility of the articles published.
This management report systematizes information that permits the mapping of the framework of the editorial processing of the manuscripts submitted to the Paidéia during the year 2018. Comparison of the data accumulated over the last three years shows that the journal has gradually and consistently strengthened its editorial process, establishing itself as a unifying space for the knowledge produced in the field of Psychology. 
However, some fragilities need to be considered, such as the limited number of international collaborations and the concentration of ad hoc consultants in the Southeastern states. The low percentage of articles from foreign authors is a limitation as well. Overcoming these challenges requires the adoption of specific strategies.

One positive aspect to be highlighted in this report is the adoption of the publication of the full text of the articles in English in 2012, which gives greater international visibility to the articles published in the journal. The journal has ensured its inclusion in new international indexes, which contributes to the internationalization efforts.

Another positive point is that the rate of "endogeneity" of the journal (articles from authors of the University of São Paulo) $7.1 \%$ of the articles published in 2018 - although it had a slight increase, remained stable, when considering the historical series. This rate was $10.4 \%$ in 2017 (Santos, 2018), 5.3\% in 2016 (Santos, 2017). In other words, Paidéia proves to be a journal that is truly open to the Brazilian scientific community and, in recent years, increasingly oriented towards the international community, according to the guidelines of our Action Plan agreed upon with CAPEs in 2011-2012, when the journal ran for and won a Call aimed at levering the internationalization of the scientific journals of all knowledge areas. Paidéia won the Call, recognizing its excellent contribution in the editorial context. Since then, the journal has honored all of the commitments assumed in that Action Plan, rapidly turning into an international publication.

As a result of the continuing efforts that have been systematically undertaken over the last few years, Paidéia today occupies a prominent place among the publications in the field of psychology, among the six national journals in the area classified as A1 (Qualis Journals Commission of Psychology, 2016).

Regarding the communication of science, it must be remembered that the publication may be through various means, with scientific journals highlighted due to quality control, greater credibility, consistency, and visibility of information. Scientific knowledge is mainly derived from original research, submitted to the peer review process and published in an indexed journal, with attention to the use and impact of the information conveyed. Being indexed in specialized or multidisciplinary databases is the seal of quality of a journal.

Considering the great increase in the national scientific production in recent years, due to a stimulus policy that is unfortunately often confused with the deleterious productivism resulting from the pressure to publish, it is highly desirable for national journals to give greater transparency to their publishing processes. Thus, this Management Report complies with the social mission of returning to society the result of public investments that have been allocated in recent years to the field of science and technology. Finally, the scientific journals play an important role in evaluating the quality and dissemination of the knowledge produced in the area of Psychology. They are the principle means of publication and also the most prestigious and credible.

\section{References}

Comissão Qualis Periódico da Psicologia. (2015). Qualis periódico da psicologia: Atualização 2015. Brasília, DF: Coordenação de Aperfeiçoamento de Pessoal de Nível Superior. Retrieved from https://www.capes.gov. br/images/stories/download/avaliacaotrienal/Docs de_area/qualis/relatorio_atualizacao_qualis_2015_ psicologia_23_06_15.pdf

Santos, M. A. (2016). Paidéia: Management report - 2015. Paidéia (Ribeirão Preto), 26(63), 1-6. doi:10.1590/198243272663201601

Santos, M. A. (2017). Paidéia: Management report - 2016. Paidéia (Ribeirão Preto), 27(66), 1-6. doi:10.1590/198243272766201701

Santos, M. A. (2018). Paidéia: Management report - 2017. Paidéia (Ribeirão Preto), 28, e2801. doi:10.1590/1982$4327 \mathrm{e} 2801$

Manoel Antônio dos Santos is an Full Professor of the Faculdade de Filosofia, Ciências e Letras de Ribeirão Preto at the Universidade de São Paulo, Ribeirão Preto-SP, Brazil and Editor Responsible of Paidéia.

How to cite this management report:

Santos, M. A. (2019). Paidéia: Management report 2018. Paidéia (Ribeirão Preto), 29, e2940. doi: http://dx.doi.org/10.1590/1982-4327e2940 